\title{
Atitudes de Estudantes Universitários para com a Homossexualidade Masculina e a AIDS
}

\author{
dson Laino ${ }^{1}$ \\ Maria Cristina Corino da Fonseca ${ }^{2}$ \\ swaldo Martins Rodrigues Júnior ${ }^{3}$
}

\section{ESUMO}

LA $\quad$, ;F S CA, M. C. C.; R DR GU S Jr., . M. Atitudes de es tudantes universitários para com a homossexualidade e a A DS. R.B.S.H. 1(2):1990.

Com o objetivo de se pesquisar a atitude de estudantes uni versitários do sexo masculino quanto à homossexualidade masculina e a A DS, elaborou se um questionário que foi aplicado a 67 estu dantes de Administração de mpresas.

s estudantes referem não ter vínculos de amizade com homossexuais masculinos $(73,14 \%)$ e indiferença quanto à presença de homossexuais $(82,09 \%)$.

Quanto à A DS, a promiscuidade foi apontada como o fator predisponente $(56,72 \%)$, sendo que $49,25 \%$ a reconhecem como associada à deficiência imunológica.

A diminuição dos contatos sexuais com diferentes parceiros a partir de 1984 foi referida por $58,21 \%$.

preconceito para com a homossexualidade aparece em $34,34 \%$ dos pesquisados, referindo a como "sem vergonhice" e doença.

Assim como outros grupos, os estudantes universitários apresen tam preconceitos para com a homossexualidade masculina e a A DS. Unitermos: homossexualidade masculina, A DS, atitudes, estudantes universitários.

1. Graduando em Psicologia pelas Faculdades São Marcos, SP

2. Graduando em Psicologia pelas Faculdades São Marcos, SP.

3. Psicólogo clínico, psicoterapeuta sexual do nstituto H. llis (SP), professor assis tente de Teorias e Técnicas Psicoterápicas das Faculdades São Marcos (SP). 


\section{SUMMARY}

LAINO, E.; FONSECA, M. C. C.; RODRIGUES Jr., O. M. Male college student's attitudes toward male homosexuality and AIDS. R.B.S.H. 1(2): 1990 .

In order to verify the attitude of male college students toward male homosexuality and AIDS a questionary was developed and 67 students of administration answered to it.

The students refered not to have homosexual friends $(73.14 \% 0)$ and indiference to the presence of male homosexuals in their relationships (82.09\%).

AIDS was conected to promiscuity (56.72\%) and as a imunodefficiency (49.25\%). After 1984, 58.21\% refered that they had a diminuition of sex partners.

The preconceptuous attitude toward homosexuality was present in $34.34 \%$ of the college students when they refered male homosexuality as a sickness or lack of virtue or moral qualities.

As within other populations the preconceptuous attitudes toward male homosexuality and AIDS is present among male college students. Uniterms: male homosexuality, AIDS, attitudes, male college students.

\section{INTRODUÇÃO}

Com o objetivo de correlacionar o preconceito de universitários homens quanto a homossexualidade masculina e a AIDS, elaborou-se um questionário que avaliasse a existência do preconceito.

Para tanto, buscou-se a população universitária dentro de um curso onde existe um predomínio de estudantes do sexo masculino: alunos de Administração de Empresas de uma faculdade privada. contidos.

Definimos, para apresentação deste trabalho, os termos nele

\section{AIDS}

É a abreviação, em inglês, de Síndrome da Deficiência Imunológica Adquirida. A AIDS é provocada por vírus de vários tipos, que penetram nas células de defesa do organismo, diminuindo sua capacidade imunológica, isto é, de defesa frente ao ataque do vírus.

A pessoa acaba morrendo não de AIDS em si, mas das infecções e tumores malignos que desenvolve por causa da sua imunidade.

A AIDS foi detectada nos EUA, em 1979, quando hospi- 
tais de Los Angeles começaram a receber pacientes homens com moléstias raras que só se manifestam em indivíduos com sistema imunológico gravemente deficiente. No Brasil, os primeiros casos foram diagnosticados em 1982. EUA, Brasil, Uganda e França são os países com mais casos de AIDS.

A AIDS pegou de surpresa a classe médica. Ninguém sabia do que se tratava e não havia pessoal treinado para lidar com essa doença. Como seus portadores são principahnente homossexuais, todo preconceito contra esse grupo explodiu: os moralistas colocando a doença como castigo de Deus, os puritanos culpando a liberdade sexual... A doença gerou pânico e caos na sociedade, sendo utilizada para incutir o medo da liberdade sexual e a culpa pela homossexualidade (Suplicy, 1987).

\section{Homossexualidade}

Padrão de relacionamento sexual entre membros do mesmo sexo, baseado na atração mútua. Pode limitar-se a fantasias e a sensações sexuais, mas geralmente envolve atividades sexuais - desde beijos, afagos, bolinações e masturbação mútua até felação e coito, estímulo lingual e tribadismo entre mulheres. Os dados de Kinsey, de aproximadamente 40 anos atrás, indicam que $37 \%$ dos homens adultos da população branca e $13 \%$ das mulheres adultas da população branca, nos EUA, tiveram alguma experiência homossexual avançada até o ponto do orgasmo. Bem menos, todavia, são os exclusivamente homossexuais por grande parte de suas vidas: $8 \%$ entre os homens e de 1 a $3 \%$ entre as mulheres (Goldenson e Anderson, 1986).

Nas sociedades da Roma e da Grécia antigas, a homossexualidade não era alvo de reprovação. Por volta dos 10 anos o jovem tinha sua iniciação sexual com homens. Por vezes, essa iniciação era com monges, a quem era confiada a educação dos jovens. Entre os romanos, a homossexualidade era tida como normal, haja vista que relações heterossexuais tinham cunho procriador. Isto durou até meados da era cristã; a partir de então a homossexualidade passou a ser alvo de preconceitos.

Entre os romanos, o homossexualismo era um sentimento interior e, naquela época, a solicitação do mundo e a expressão do amor, pois a mulher era algo alheio e distante (Roussele, 1984).

Em outras sociedades antigas, como a egípcia, a assíria e a hebraica, a homossexualidade era proibida por lei. Em civilizações do Oriente Próximo e do Mediterrâneo Oriental, adoravam-se deuses, cujos ritos incluíam relações sexuais com sacerdotes e sacerdotisas homossexuais. 
Mesmo em sociedades onde as relações homossexuais eram permitidas, esse comportamento era restrito aos adultos com jovens púberes. Tanto gregos como romanos desprezavam a homossexualidade quando esta era a orientação predominante.

Acredita-se que as restrições à homossexualidade tenham se iniciado com a repressão judaico-cristã, mas outras sociedades, no decorrer da história, também proibiram a homossexualidade. Em 1804, na França, com a proclamação do Código de Napoleão, havia a permissão da expressão homossexual por livvre escolha entre dois adultos.

Apesar do comportamento homossexual ser muito antigo, só nas modernas sociedades urbanas é que passa a existir a identidade homossexual. Estas sociedades encaram cada vez mais a homossexualidade como um comportamento alternativo, diminuindo, assim, o sentimento de culpa existente nos meios onde a orientação é estritamente homossexual. Contudo, só em 1973 a Associação Psiquiátrica Americana retirou a homossexualidade da classe das doenças mentais (Suplicy, 1987).

Um importante elemento desencadeante da homossexualidade são os ambientes que segregam pessoas do mesmo sexo: conventos, prisões, internatos, manicômios (Conceição et al., 1981).

A punição social da homossexualidade dá-se mais sobre a homossexualidade masculina e menos sobre o lesbianismo, nome pelo qual é conhecida a homossexualidade feminina, o qual tende a ser mais tolerado e menos aparente socialmente. Atualmente, há países onde a homossexualidade é legalizada: na Alemanha Oriental para maiores de 18 anos desde 1968; na Bulgária para maiores de 21 anos; na Hungria para maiores de 20 anos; na Polônia aos 15 anos; na Tchecoslováquia e Iugoslávia aos 18 anos. Porém, é ilegal em Cuba, China, Laos, Líbia, Romênia, Albânia, Rússia, Austrália, Chile, Índia, Nova Zelândia, Tunísia, Uganda (López-Ibor, 1986).

A incidência de homossexuais na população é de cerca de 10 a $12 \%$, segundo pesquisas efetuadas em países da Europa e nos Estados Unidos (Lima, 1981). Kinsey (1954) apontou 37\% de homens e $13 \%$ de mulheres, nos EUA, como tendo tido alguma experiência homossexual até o orgasmo no período entre a adolescência e a velhice.

Uma amostra de homens brasileiros (Rodrigues Jr., Monesi e Costa, 1990) aponta que $13 \%$ de homens com queixas de disfunções sexuais já apresentaram relacionamentos adolescentes de cunho homossexual, o "troca-troca". 
Especula-se muito sobre a homossexualidade, muito mais pela condição de servirem-se os homossexuais a aparição pública (caráter exibicionista) do que de modo mais científico.

A homossexualidade sempre existiu e podemos constatá-la nos relatos históricos dos gregos que formavam pares de soldados para irem à guerra.

Neste século, nas últimas décadas, os movimentos contra os preconceitos homossexuais e contra a homofobia têm permitido a expressão sexual dos homossexuais, tornando este comportamento mais normal e mais explícito, não se devendo no entanto crer que este com-portamento esteja tendo sua ocorrência aumentada simplesmente (Rodrigues Jr., 1988).

\section{MATERIAL E MÉTODOS}

Os pesquisandos que responderam o questionário eram 67 graduandos do curso de Administração de Empresas de uma faculdade privada, do sexo masculino, e suas idades variaram de 20 a 42 anos, tendo como média 27 anos e mediana 22 anos.

As questões utilizadas na coleta de dados e suas explicações seguem a seguir.

1. Através desta, a intenção foi verificar se o pesquisando relaciona-se amistosamente com homossexuais:

- Existe algum homossexual dentro do seu círculo de amizades? Sim...... Não......

2. Desta vez, a intenção foi avaliar o grau de preconceito para com o homossexual:

- Se há ou se houvesse algum, você: a) se afastaria; b) criticaria; c) seria indiferente.

3. Esta questão intencionou buscar o preconceito com relação à doença AIDS:

- Você encara a AIDS como: a) castigo de Deus; b) doença de homossexuais; c) descuido nos relacionamentos (promiscuidade); d) deiciência imunológica.

4. O objetivo da questão a seguir foi saber se o pesquisando alterou a intensidade de relacionamentos através da ampla divulgação da doença:

- Você diminuiu o número de relacionamentos sexuais após a grande divulgação da AIDS a partir de 1984? Sim ...... Não......

5. Com esta questão, tentou-se enfocar tanto a informação sobre o assunto quanto o preconceito existente:

- Você acredita que a homossexualidade é: a) doença; b) 
sem-vergonhice; c) tem causa psicológica; d) deve-se a problemas educacionais (família); e) é um comportamento alternatïvo; f) outros, quais?.....

Determinaram-se as freqüências de respostas às alternativas das questóes.

\section{RESULTADOS}

Observou-se que $73,14 \%$ dos pesquisandos não mantêm vínculo de amizade com homossexuais masculinos, sendo que 1,49\% da amostra absteve-se de responder.

Quanto ao grau de preconceito com o homossexual, notou-se que $82,09 \%$ seria indiferente à presença de homossexuais em seu convívio; $10,45 \%$ afastar-se-ia; $5,97 \%$ criticaria, sendo que também houve $1,49 \%$ de abstenção para esta questão.

Questionados quanto ao preconceito com relação à AIDS, observou-se que $56,72 \%$ da amostra acredita na existência do descuido nos relacionamentos sexuais (promiscuidade); $49,25 \%$ encara a AIDS como deficiência imonológica; $5,98 \%$ acredita que seja uma doença de homossexuais e 2,98\% afirma ser um "castido de Deus". Foram oferecidas quatro alternativas para esta questão e 14,93\% dos pesquisandos combinaram as alternativas (mais de uma resposta), sendo que, assim, a somatória das porcentagens obtidas é superior a $100 \%$ (Figura 1).

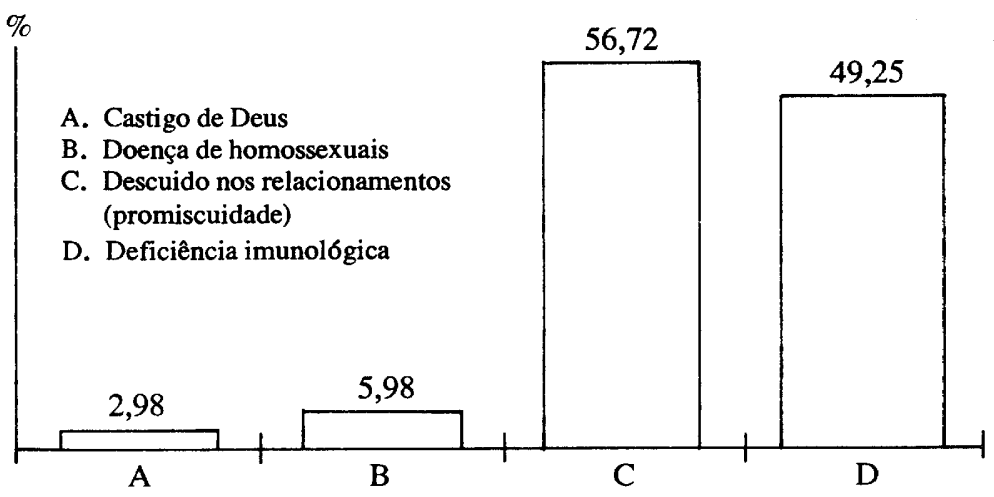

Figura 1 - Atitudes do estudante universitário com relação à AIDS*.

* Os pesquisandos optaram por mais de uma alternativa. 
Com relação à alteração na intensidade de relacionamentos, após a grande divulgação da AIDS, 58,21 \% da amostra afirma ter diminuído o número de relacionamentos sexuais.

A causa da homossexualidade foi apontada como psicológica por $65,65 \%$ dos pesquisandos; $41,80 \%$ encara, como causa, problemas educacionais (família); 20,90\% afirma que a homossexualidade é "sem-vergonhice"; $17,90 \%$ a considera como comportamento alternativo; $13,44 \%$ a vê como doença e $10,44 \%$ da população descreve outros motivos: "não sei explicar, talvez loucura, doença biológica, não consigo entender e não admito"; "fez e gostou"; "cada caso tem que ser analisado individualmente, pois pode vir de várias fontes"; "acredito que é um pouco de cada"; "distúrbios de personalidade"; "safadeza"; "este comportamento vem de dentro da pessoa, talvez eles tenham nascido em época errada”.

Também nesta questão os pesquisandos combinaram as respostas $(43,28 \%)$ e, portanto, a somatória das porcentagens não será igual a $100 \%$ (Figura 2).

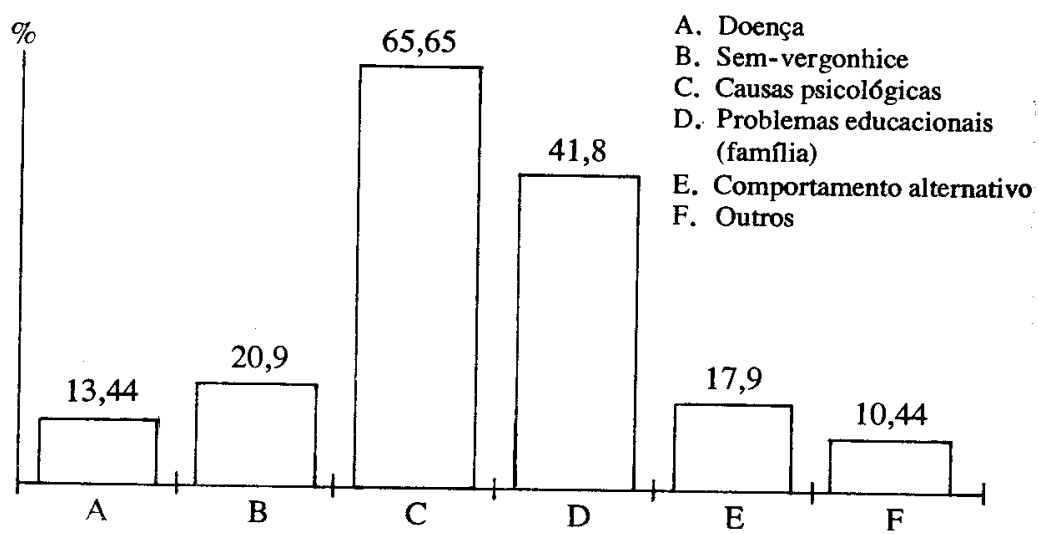

Figura 2 - Posicionamento do estudante universitário quanto à homossexualidade*.

* Os pesquisandos optaram por mais de uma alternativa.

\section{COMENTÁRIOS}

A questão que refere o vínculo de amizade com homossexuais. masculinos poderia ser melhor formulada, uma vez que o pesquisando pode não estar percebendo a existência de algum em seu meio. 
Notou-se muita euforia e agitação tanto nas explicações preliminares para aplicação do questionário como durante a mesma, gerada pelo tabu em torno da sexualidade.

Os aplicadores não tiveram dificuldades para expôr os objetivos da pesquisa e nem mesmo para aplicá-la, mas sim para controlar a ansiedade causada pelo assunto polêmico.

\section{CONCLUSÕES}

Estudantes universitários, de um curso de Administração de Empresas, aparentemente não mantêm contatos sociais com homossexuais masculinos, ao menos homossexuais declarados, apesar de um número comparativamente maior referir indiferença quanto à convivência com homossexuais.

Existe uma falta de informação entre os estudantes de Administração de Empresas com relação à AIDS, onde apenas 49,25\% da amostra a refere como deficiência imunológica e uma minoria a refere como doença de homossexuais e castigo de Deus.

Nesta amostra, $58,21 \%$ dos pesquisandos demonstram ter diminuído o número de relacionamentos sexuais. Comparando-se os dados obtidos, observa-se que $29,86 \%$ dos pesquisandos acredita em descuido (prosmicuidade) como causa da AIDS e respondem ter diminuído o número de relacionamentos sexuais; $25,38 \%$ da amostra, mesmo acreditando em promiscuidade, não diminuiu o número de relacionamentos sexuais, o que sugere falta de informação com relação à AIDS.

Da amostra, 20,9\% afirma que a homossexualidade é "semvergonhice" e os $13,55 \%$ que vêem a homossexualidade como doença não são diferentes de outras populações, tais como, médicos ginecologistas que apresentam preconceitos negativos com relação a homossexuais (Rodrigues Jr., Costa, Di Sessa, 1990).

Visto que o preconceito é algo que existe contra todo e qualquer grupo que desvia-se dos padrões sociais, e isso foi confirmado através dos dados obtidos com a pesquisa, pode-se afirmar que também no meio universitário, muitas vezes, há desinformação com relação e assuntos atuais.

Entre os pesquisandos que descrevem outros motivos, quatro também referem atitudes negativas para com a homossexualidade (doença e distúrbio de personalidade).

O estudo sobre a homossexualidade e sobre os comportamentos homossexuais deve ser encampado por profissionais sérios que também divulguem suas experiências e resultados, de modo que a popu- 
lação leiga, em especial, desenvolva uma atitude mais adequada e por conseguinte mais coerente e menos preconceituosa para com a homossexualidade e os homossexuais. Naturalmente, devemos prescrever o direito à escolha e às preferências pessoais, inclusive o não gostar de homossexuais, porém sem que haja a indisposição prévia ao contato e ao relacionamento interpessoal, sem o pré-conceito.

\section{BIBLIOGRAFIA}

1. CONCEIÇÃO, I. S. C.; SILVA, A. M.; CONCEIÇÃO, J. Q. Homossexualismo feminino no manicômio judiciário de São Paulo. In Cavalcanti, R. C.; Vitiello, N. (ed.). Sexologia I. Textos do I Encontro Nacional de Sexologia. Rio de Janeiro, Femina Livros, 1984.

2. GOLDENSON; R. M.; ANDERSON, K. N. Dicionário de Sexo. São Paulo, Editora Atica, 1986.

3. KINSEY, A. C.; POMEROY, W. B.; MARTIN, C. E.; GEBHARD, P. H. Conduta Sexual da Mulher. Rio de Janeiro, Livraria Atheneu, 1954.

4. LIMA, H. A. M.; CONCEIÇÃO, I. S. C.; SHUTZER, L.; PERICINATTO, M. C. Homossexualismo feminino. In Cavalcanti, R. C.; Vitiello, N. (ed.). Sexologia I. Textos do I Encontro Nacional de Sexologia. Rio de Janeiro, Femina Livros, 1984.

5. LOPEZ-IBOR, A. J. M. (coord.). Biblioteca Básica de Educação Sexual: o homossexualismo masculino. Rio de Janeiro, Editora Século Futuro, 1986.

6. RODRIGUES Jr., O. M.; MONESI, A. A.; COSTA, M. Sexual activities in adolescence of sexually dysfunctioning men in Brasil. International Journal of Impotence Research, Basic and Clinic Studies 2(2) 52:183-84, 1990.

7. RODRIGUES Jr., O. M. Desvios sexuais. Mimeografado. Curso de Preparação de Orientadores em Sexualidade. São Paulo, Faculdades São Marcos, 1988.

8. RODRIGUES Jr., O. M.; COSTA, M.; DI SESSA, S. R. A Opinião do Ginecologista sobre a Homossexualidade e a Bissexualidade. Sexus, no prelo, 1990.

9. ROUSSELLE, A. Pornéia: Sexualidade no Mundo Antigo. São Paulo, Editora Brasiliense, 1984

10. SUPLICY, M. Conversando sobre Sexo. São Paulo, Círculo do Livro, 1987.

11._. Sexo para Adolescentes. São Paulo, Editora FTD, 1988. 